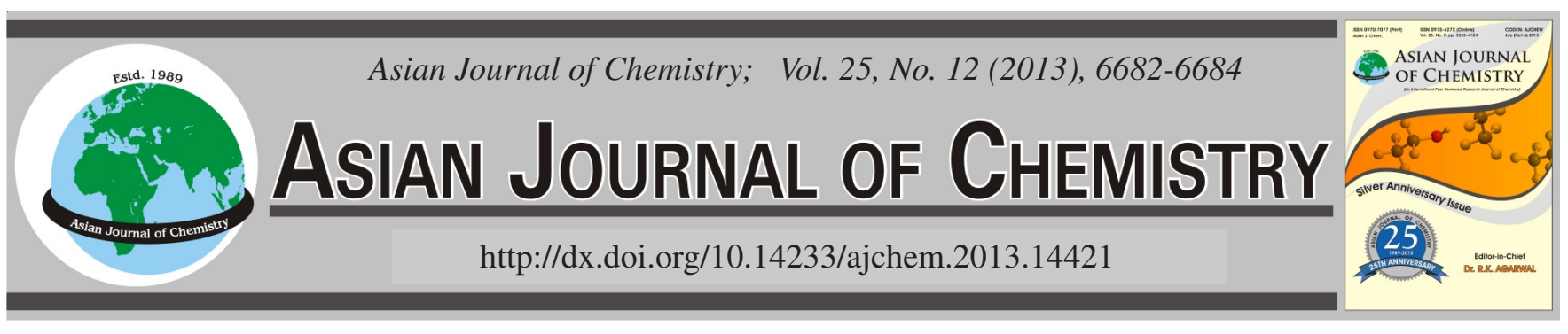

\title{
Determination of Eight Mineral Elements in Chinese Bayberry (Myrica rubra) from Zhejiang, China
}

\author{
Yongzhi Zhang ${ }^{1}$, Chuangmu Zheng ${ }^{2, *}$, Ganguun Wang ${ }^{1}$ and XueZhu Ye ${ }^{1}$
}

${ }^{1}$ Institute of Quality and Standard for Agricultural Products, Zhejiang Academy of Agricultural Sciences, Hangzhou, Zhejiang 310021, P.R. China ${ }^{2}$ Institute of Quality Standards \& Testing Technology for Agro-products, Chinese Academy of Agricultural Sciences, Beijing 100081, P.R. China

*Corresponding author: Fax: +86 10 82106509; Tel: +86 10 82106506; E-mail: zcmcaas@ 126.com

(Received: 8 August 2012;

Accepted: 27 May 2013)

AJC-13548

\begin{abstract}
Eight mineral elements in Chinese bayberry were measured by inductively coupled plasma-mass spectrometry. Twenty eight samples of Myrica rubra collected from Zhejiang province were investigated. Concentration of potassium, calcium, magnesium, manganese, copper, arsenic, lead and cadmium were measured. The macronutrients and micronutrients levels for the samples were determined between 597.1 and $1564.2 \mathrm{mg} / \mathrm{kg} \mathrm{K}, 73.4$ and $143.5 \mathrm{mg} / \mathrm{kg} \mathrm{Ca}, 47.8$ and $81.9 \mathrm{mg} / \mathrm{kg} \mathrm{Mg}, 0.9$ and $8.2 \mathrm{mg} / \mathrm{kg} \mathrm{Mn}$ and 0.1 and $1.3 \mathrm{mg} / \mathrm{kg} \mathrm{Cu}$. The heavy metals As, $\mathrm{Pb}$ and $\mathrm{Cd}$ were ranged from 0.054 to $0.096,0.0053$ to 0.14 and 0.00038 to $0.0068 \mathrm{mg} / \mathrm{kg}$, respectively.
\end{abstract}

Key Words: Chinese bayberry, Myrica rubra element.

\section{INTRODUCTION}

Myrica rubra also called yangmei, yamamomo, Chinese bayberry, Japanese bayberry, red bayberry, Yumberry, Waxberry or Chinese strawberry tree, is a subtropical tree grown for its sweet, crimson to dark purple-red, edible fruit. It is native to eastern Asia, mainly in China, where it has been grown for at least 2000 years. Chinese cultivation is concentrated south of the Yangtze River, where it is of considerable economic importance. The niche of Myrica rubra is forests on mountain slopes and valleys at altitudes of 100-1500 m. It is native to Fujian, Guangdong, Guangxi, Guizhou, Hainan, Hunan, Jiangsu, Jiangxi, Sichuan, Yunnan, Zhejiang and Taiwan, also naturalized in Japan, Nepal, Korea and the Philippines ${ }^{1}$. Especially in Zhejiang province, as the main producing area, the percentage of its planting area and yield was 20 and $30 \%$, respectively in China ${ }^{2}$.

Potassium, calcium and magnesium as macronutrients are required in large quantities by the human body. Manganese, copper belong to the category of micronutrients are essential components of biological structures, but at the same time they can be toxic at concentrations beyond those necessary for their biological functions ${ }^{3}$. The arsenic, cadmium and lead, as toxic elements, are harmful for human body. For this reason, WHO and FAO determined the PTWI (Provisional Tolerable Weekly Intake) is $0.015,0.007$ and $0.025 \mathrm{mg} / \mathrm{kg}$ bw (body weight), respectively for arsenic, cadmium and lead ${ }^{4}$. Meanwhile the MLs (maximum levels) of those three elements according to the Chinese mandatory national standards GB 2762-2005 maximum levels of contaminants in food are 0.5, 0.05, 0.2 $\mathrm{mg} / \mathrm{kg}$, respectively.

Low detection limits and the speed of inductively coupled plasma-mass spectrometer (ICP-MS) make the technique well suited to analyze trace elements in samples. The ICP-MS method overcomes the sensitivity limitations of inductively coupled plasma-atomic emission spectrometry (ICP-AES) and the time consumption of electrothermal atomic absorption spectrophotometry by providing multi-element measurement capability in a single run 5 .

The goal of this work was to measure mineral nutrients and toxic metal contents of Chinese bayberry originating in Zhejiang province, China by ICP-MS. Microwave digestion method using concentrated nitric acid was applied for sample digestion. The metal (K, $\mathrm{Ca}, \mathrm{Mg}, \mathrm{Mn}, \mathrm{Cu}, \mathrm{As}, \mathrm{Pb}, \mathrm{Cd}$ ) concentrations in 28 samples were determined. The software used for statistic analysis was the Predictive Analytics SoftwarePASW Statistics (version 18.0).

\section{EXPERIMENTAL}

Sampling and pre-treatment of samples: Twenty eight samples of Myrica rubra were collected from the main planting area in Zhejiang province during the harvest season in 2011. Then the samples were transported to the laboratory, first flushed with tap water then with deionized water, blotted up it with filter paper, removed the core and mashed as homogenate for analysis. 
The method of microwave digestion was used to digest the samples, $c a$. $1 \mathrm{~g}$ sample was accurately weighed and transferred into TFM (tetrafluormethaxil) vessel, followed by adding $4.0 \mathrm{~mL} 65-70 \% \mathrm{HNO}_{3}$, cold digestion over night, then added $2.0 \mathrm{~mL} 30 \% \mathrm{H}_{2} \mathrm{O}_{2}$. The vessels were capped and placed in the microwave system and digested using the parameters listed in Table-1. At the end of the program, the vessels were cooled to room temperature in a fume hood and the pressure inside the vessels slowly released. After cooling the digested samples were transferred to $50 \mathrm{~mL}$ graduated polypropylene centrifuge tubes, washed three times with double-deionized water (DDW) to a volume of $50 \mathrm{~mL}$ and filtered by filter paper to remove any remaining undissolved solid particles that might block the nebulizer. Process a reagent blank in the same way.

\section{TABLE-1}

OPERATING PARAMETERS, TEMPERATURE PROGRAMS AND DIGESTION REAGENTS FOR MICROWAVE SYSTEM

\begin{tabular}{cc}
\hline Power $(\mathrm{W})$ & $0-1,200$ \\
Vessel volume $(\mathrm{mL})$ & 55 \\
Sensors control & Temperature \\
Ramp time $(\mathrm{min})$ & 10 \\
Hold time $(\mathrm{min})$ & 30 \\
$\mathrm{Hold}$ temperature $\left({ }^{\circ} \mathrm{C}\right)$ & 185 \\
$\mathrm{HNO}_{3} / \mathrm{H}_{2} \mathrm{O}_{2}$ digestion mixture & $4.0 \mathrm{~mL}$ conc. $\mathrm{HNO}_{3}$ and $2.0 \mathrm{~mL}$ \\
$(\mathrm{~mL})$ & $30 \% \mathrm{H}_{2} \mathrm{O}_{2}$ \\
\hline
\end{tabular}

An inductively coupled plasma mass spectrometry (ICPMS) was used for eight elements determination; the operating parameters are shown in Table-2. Sample solution and internal standard were injected simultaneous through a three-way pipe. The solution containing $1 \mu \mathrm{g} / \mathrm{L}$ of rhodium $(\mathrm{Rh})$ and rhenium (Re) was used as internal standard. The reliability of the method was confirmed by using a certified reference material (GBW 10016, National research centre for certified reference materials, CRM Tea).

\begin{tabular}{cc}
\multicolumn{2}{c}{ TABLE-2 } \\
ICP-MS OPERATING CONDITIONS \\
\hline Auxiliary (L/min) & 0.74 \\
Nebuliser (L/min) & 0.85 \\
Forward power (W) & 1223.5 \\
Analogue detector (V) & 2060 \\
PC detector (V) & 1300 \\
Resolution & Standard \\
Dwell (ms) & 100 \\
Number of replicates & 3 \\
Peri-pump (r/min) & 20 \\
\hline
\end{tabular}

The determination of As can be disturbed by the presence of chloride ions. The polyatomic ion ${ }^{40} \mathrm{Ar}{ }^{35} \mathrm{Cl}$ interferes with ${ }^{75} \mathrm{As}$. In many cases, spectroscopic interferences can be avoided by choosing alternative isotopes, but this method is not applicable to mono-isotopic elements such as As. An elemental equation of correction was then used ${ }^{6}$. The equation used the naturally occurring isotopes ratios of relevant elements to estimate and allow the subtraction of isobaric interferences:

$$
{ }^{75} \mathrm{As}=1 \times\left({ }^{75} \mathrm{C}\right)-3.127 \times\left({ }^{77} \mathrm{C}\right)+0.874 \times\left({ }^{82} \mathrm{C}\right)
$$

where ${ }^{75} \mathrm{C},{ }^{77} \mathrm{C}$ and ${ }^{82} \mathrm{C}$ are counts on $\mathrm{m} / \mathrm{z} 75,77$ and 82 , respectively.

\section{RESULTS AND DISCUSSION}

The ICP-MS (Thermo Fisher Scientific Inc, USA) was employed to determine 8 elements ( $\mathrm{K}, \mathrm{Ca}, \mathrm{Mg}, \mathrm{Mn}, \mathrm{Cu}, \mathrm{As}$, $\mathrm{Pb}$ and $\mathrm{Cd}$ ) in samples. The descriptive statistics results were listed in Table-3. It showed that in the Chinese bayberry was abundance of macronutrients, $\mathrm{K}, \mathrm{Ca}$ and $\mathrm{Mg}$, the average concentration was $1083.4,100.8$ and $59.2 \mathrm{mg} / \mathrm{kg}$, respectively. The concentrations of $\mathrm{Mn}, \mathrm{Cu}$ undulated greater than that of macronutrients ( $\mathrm{K}, \mathrm{Ca}$ and $\mathrm{Mg}$ ). The RSD (relatively standard deviation) were greater than $35 \%$, especially for $\mathrm{Cu}$ it was $49.8 \%$. That means the source of contamination of these two metals were multifarious. The same results were observed for the heavy metals, $\mathrm{Pb}$ and $\mathrm{Cd}$, the RSD was 56.2 and $80.2 \%$, respectively. In recent years the introduction of methylcyclopentadienyl manganese tricarbonyl (MMT) as an octane enhancer in gasoline resulted in the higher concentration of $\mathrm{Mn}$ in the vehicle exhaust ${ }^{7}$. As the planting area of Chinese bayberry are always near the road for the convenience of transportation, therefore the $\mathrm{Mn}$ in the vehicle exhaust can affect the concentration in the samples. The multiformity of geographical distribution of $\mathrm{Pb}$ and $\mathrm{Cd}$ in the mountainous area ${ }^{8}$ also resulted in the great undulation of its concentrations in samples. However the concentrations of three toxic elements, As, $\mathrm{Pb}$ and Cd, were under the MLs according to GB 2762-2005, so it's safe for human consumption.

The histogram of $\mathrm{K}, \mathrm{Ca}, \mathrm{Mg}, \mathrm{Mn}, \mathrm{Cu}, \mathrm{As}, \mathrm{Pb}, \mathrm{Cd}$ concentrations in 28 Chinese bayberry samples presented that the distributions of frequency of elements, $\mathrm{K}, \mathrm{Ca}, \mathrm{Mg}, \mathrm{Cu}$ and $\mathrm{As}$, were closed to normal distribution. That indicated there has not strong additional factors which affect their concentrations in the samples. On the contrary, the distributions frequencies of $\mathrm{Pb}$ and $\mathrm{Cd}$ were all greater in low concentration samples than high ones, which showed there have pollutions in some samples, which lead to a few samples of high concentration of $\mathrm{Pb}$ and $\mathrm{Cd}$. With the development of rural enterprise, the pollution of higher concentration and larger region of $\mathrm{Pb}$ and $\mathrm{Cd}$ in planting area as a possible reason for the contamination of $\mathrm{Pb}$ and $\mathrm{Cd}$ in the samples ${ }^{9}$.

TABLE-3

DESCRIPTIVE STATISTICS OF K, Ca, $\mathrm{Mg}, \mathrm{Mn}, \mathrm{Cu}, \mathrm{As}, \mathrm{Pb}, \mathrm{Cd}$ CONCENTRATIONS IN 28 CHINESE BAYBERRY SAMPLES (mg/kg; FRESH MASS OF THE EDIBLE PART)

\begin{tabular}{cccccccccc}
\hline Elements & $\mathrm{K}$ & $\mathrm{Ca}$ & $\mathrm{Mg}$ & $\mathrm{Mn}$ & $\mathrm{Cu}$ & $\mathrm{As}$ & $\mathrm{Pb}$ & $\mathrm{Cd}$ \\
\hline Maximum & 1564.2 & 143.5 & 81.9 & 8.2 & 1.3 & 0.096 & 0.14 & 0.0068 \\
Minimum & 597.1 & 73.4 & 47.8 & 0.9 & 0.1 & 0.054 & 0.0053 & 0.00038 \\
Median & 1062.1 & 99.4 & 57.4 & 5.2 & 0.5 & 0.071 & 0.046 & 0.0019 \\
Average & 1083.4 & 100.8 & 59.2 & 5.3 & 0.5 & 0.072 & 0.061 & 0.0023 \\
RSD (\%) & 17.8 & 15.2 & 14.5 & 36.7 & 49.8 & 15.40 & 56.20 & 80.20 \\
\hline
\end{tabular}




\section{Conclusion}

As Chinese bayberry fruit is an abundant source of phenolic compounds ${ }^{10}$, alleviates oxidative stress extracts ${ }^{11}$ and is an important dietary component for some populations in China. It is needful to understand the components of mineral and toxic elements in Chinese bayberry fruits. The results showed that in the Chinese bayberry also are abundant of macronutrients $\mathrm{K}, \mathrm{Ca}$ and $\mathrm{Mg}$ in the edible part. Food safety is a focus public attention and the heavy metals contamination in fruits can induce chronic disease ${ }^{12}$. In this study the concentrations of heavy metals $\mathrm{As}, \mathrm{Pb}$ and $\mathrm{Cd}$ were under the MLs according to Chinese mandatory national standards GB 27622005 .

\section{ACKNOWLEDGEMENTS}

This work was financially supported by Analysis and Testing Technology Projects of Zhejiang province (Approved No. 2011C37005).

\section{REFERENCES}

1. A.-M. Lu and J. Allan, Flora China, 4, 275 (1999).

2. H.X. Xie, H.O. Wang, Z.C. Hu, F. Wu and L.L. Hu, Food Res. Develop., 6, 162 (2007).

3. C.G. Fraga, Mol. Asp. Med., 26, 235 (2005).

4. Codex Standard 193-1995 (Rev), Codex General Standard for Contaminants and Toxins in Food and Feed (2010).

5. P. Masson, T. Dalix and S. Bussière, Commun. Soil Sci. Plant Anal., 41, 231 (2010).

6. Y. Cai, M. Georgiadis and J.W. Fourqurean, Spectrochim. Acta B, 55, 1411 (2000).

7. B.S. Winder, A.G. Salmon and M.A. Marty, Regul. Toxicol. Pharmacol., 57, 195 (2010).

8. Z.C. Shu, D.B. Lu, Y.W. Zhu and L.L. Duan, Jiangsu Agric. Sci., 1, 339 (2011).

9. X.J. Cheng, B.P. Wang, Q.G. Fu, W.-W. Yu and L.Q. Zhang, Acta Agric. Univ. Jiangxiensis, 1, 50 (2006).

10. J.S. Bao, Y.Z. Cai, M. Sun, G.Y. Wang and H. Corke, J. Agric. Food Chem., 53, 2327 (2005).

11. Z.F. Yang, S.F. Cao and Y.H. Zheng, Food Chem., 125, 701 (2011).

12. C. Finardi, G. Pellegrini and G. Rowe, Food Policy, 37, 427 (2012). 